\title{
Induced Shear Stress Measurement in Overtopped Floodwalls
}

\author{
P. Safarian Bahri, A. Osouli, Ph.D. P.E, D. Molohon, F. Lagunas \\ Southern Illinois University Edwardsville, USA
}

\begin{abstract}
The scour generated by water overtopping floodwalls results in tilting and sometimes failure of floodwalls. The water free fall induces shear stress, which is difficult to measure, at the levee surface and if it exceeds the critical shear stress, scouring initiates. It is perceived that once a pool of water is generated at the levee crest due to scour, the induced stresses on soil surface at the pool bottom will decrease. The scour progress is stopped once the induced shear stresses at the pool bottom are less than critical shear stress; however, due to the low values of critical shear stress, the scour most likely continues for a long time. A methodology was developed in this study to measure the induced shear stresses. Based on the tests conducted in this study, the generated pool will decrease the induced shear stress until constant erosion rate is achieved. This shear stress is defined as 'equilibrium' shear stress herein.
\end{abstract}

\section{INTRODUCTION}

Floodwall overtopping is one of the main causes of levee failure during storm events such as the most recent ones that took place in New Orleans by Katrina Hurricane (Villarini et al. 2011). As the water overtops floodwall it applies a shear stress on the material causing erosion. As erosion continues, the weight of the water on the upstream will push the floodwall outward until it fails. Critical shear stress is the induced shear stress that initiates erosion. Any shear stress above critical shear stress will erode the soil surface.

The most common technique to measure critical shear stress is utilizing an open-channel flume test. Smerdon \& Beasley (1961) conducted a series of flume test on cohesive material retrieved from Missouri area. They used soil properties such as plasticity index, mean particle size, and percent clay to calculate critical shear stress. Briaud et al. (2001) developed Erosion Function Apparatus to determine the erodibility of retrieved samples using an open channel where critical shear stress could be determined graphically. Neill (1967) correlated critical shear stress to grain size, specific gravity, mean particle size, and depth of flow. Julian \& Torres (2006) proposed an estimation of critical shear stress using the percentage of silt and clay using the data they obtained from Dunn (1959) and Vanoni (1977). Similar to Hollick (1976), Clark \& Wynn (2007) compared the aforementioned methods for 25 field sites using JET device. Hanson (2002) estimated critical shear stress in a submerged jet test and based on water jet dissipation. Literature have shown that critical shear stress is a very small stress compared to the induced shear stresses caused by overtopping (Briaud et al. 2001 and Hanson 2004). Therefore, in this article, an 'equilibrium' shear stress is presented, which is greater than critical shear stress and is more representative of stresses causing erosion during overtopping of a floodwall in a storm event.

Estimating the erosion rate during floods or storm events is challenging. As the overtopping erodes material from levee crest, a pool of water is generated behind the wall at the landside. If the pool is large enough, it can dissipate the water induced stresses and eventually stop eroding to further depths. However, it is not likely for the pool depth to reach a depth where the induced shear stress at the bottom is lower than critical shear stress before failure.

In this article, eighteen simulated levee-floodwall tests were conducted to study the effect of the generated pool during floodwall overtopping on erosion rate and jet induced shear stress. Three types of soil with different plasticity indices, and three compaction levels were utilized in the construction of the levees to identify the contributing factors in induced shear stress. After generation of the pool, in all the tests, the erosion rate became constant as the pool reached a certain depth. That moment is called equilibrium condition and the induced shear stress at equilibrium condition is called equilibrium shear 
stress in this article. In levee-floodwall system after the pool is generated, this shear stress will continue eroding the soil material with a constant rate.

\section{APPARATUS AND TEST PROCEDURE}

Two scaled levee-floodwall models were constructed in the laboratory assuming full-sized levee would have $2.1 \mathrm{~m}$ high floodwall. For each scale a wooden floodwall was inserted through the levee at the crest. For 1:20 scale, a $0.49 \mathrm{~m}$ floodwall was utilized embedded in a $0.35 \mathrm{~m}$ high levee leaving $0.14 \mathrm{~m}$ exposed. For 1:2 scale, a $1.42 \mathrm{~m}$ floodwall was utilized embedded in a $0.35 \mathrm{~m}$ high levee leaving $1.07 \mathrm{~m}$ exposed to water freefall. Both scales had floodwall width of $0.23 \mathrm{~m}$. The water was pumped from a reservoir to a tank behind the floodwall with controlled constant flow-rate of $2.83 \mathrm{~m}^{3} / \mathrm{hr}$. The water then overtopped the floodwall impinging the levee surface at the crest and initiated the scouring process. Figure 1 shows a sketch model of 1:20 scaled model levee-floodwall system.

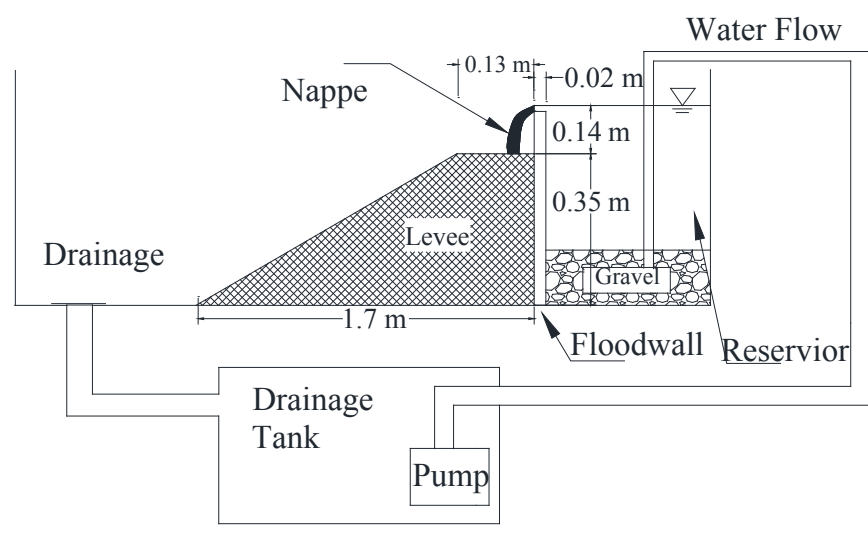

Figure 1. Sketch model of 1:20 scaled levee-floodwall system

Each test was filmed from three angles, top-view, front-view, and side-view. With initiation of scouring, the thickness of the generated nappe was measured frequently at water impingement point during the scouring process for impact velocity calculations. Nappe thickness was measured using a caliber. Initially, after the levee was built, floodwall was marked at the crest. Erosion of the levee crest was monitored throughout the test and scour depth was measured at least every 15 seconds by putting a ruler on the eroded surface vertically and reading the scour difference from the marked position. For consistency purposes, the erosion rates were calculated at $0.0127 \mathrm{~m}$ scour depths intervals. As scouring continued, a pool of water was generated at the eroded crest. The pool defused the nappe and resulted in decreasing the erosion rate. The tests were continued until the pool was deep enough so that the erosion rate was constant. The scour depth and the pool depth were documented immediately after the erosion rate became constant to measure the induced shear stress at that pool depth based on Section 4. The above procedure was followed identically for both $1: 2$ and $1: 20$ scales.

\section{MATERIAL}

For diversity of the tests, three sets of plasticity indices were utilized. Two types of soil were retrieved from banks of Mississippi River. The desired PIs of $0,6 \%$, and $9 \%$ were constructed by mixing the aforementioned two soils. For each plasticity index, three sets of standard proctor compaction levels were conducted using a calibrated hand hammer. To verify the targeted dry density, samples were taken from each layer of compacted material. The simulated levees were constructed in five layers. For each of the scales of $1: 20$ and 1:2, nine tests were performed. Table 1 shows the material specifications.

Table 1. Specifications of soil material used in 18 performed simulated levee-floodwall tests

\begin{tabular}{|c|c|c|c|}
\hline PI $C L$ & $70 \%$ & $80 \%$ & $90 \%$ \\
\hline \multirow[t]{2}{*}{0} & $1: 20$ & $1: 20$ & $1: 20$ \\
\hline & $1: 2$ & $1: 2$ & $1: 2$ \\
\hline \multirow[t]{2}{*}{$6 \%$} & $1: 20$ & $1: 20$ & $1: 20$ \\
\hline & $1: 2$ & $1: 2$ & $1: 2$ \\
\hline \multirow[t]{2}{*}{$9 \%$} & $1: 20$ & $1: 20$ & $1: 20$ \\
\hline & $1: 2$ & $1: 2$ & $1: 2$ \\
\hline
\end{tabular}

\section{INDUCED SHEAR STRESS MEASUREMENT}

The induced shear stress was measured using an adjustable arm connected to a strain gage at different elevations inside the levee-floodwall simulator. A container was connected to the end of the arm as shown in Figure 2. The floodwall was overtopped with water with the same flow-rate as the levee tests were run with. The container was filled with water to imitate the generated pool at the crest of the levee during overtopping. As the water impinged the pool of water in the container, the force was measured using the strain gage multiple times to find an average value. The induced shear stress was calculated by dividing the measured force by the area of the impinged surface which is defined by multiplying nappe thickness by the width of impingement surface. 


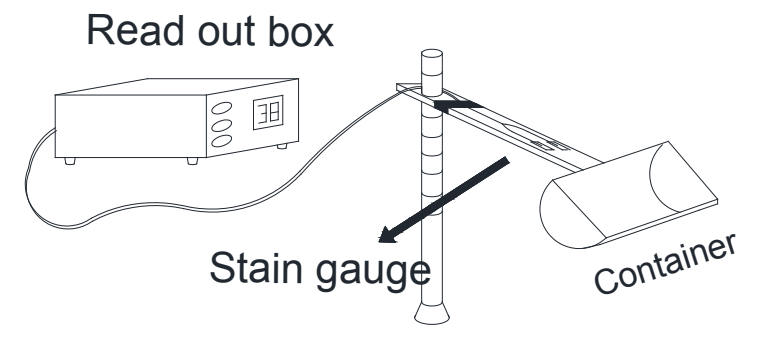

Figure 2. Sketch showing the induced shear stress measurement system

The induced shear stress was measured following the above procedure for different pool depths. An example of a combination of a certain scour and pool depth is sketched in Figure 3.

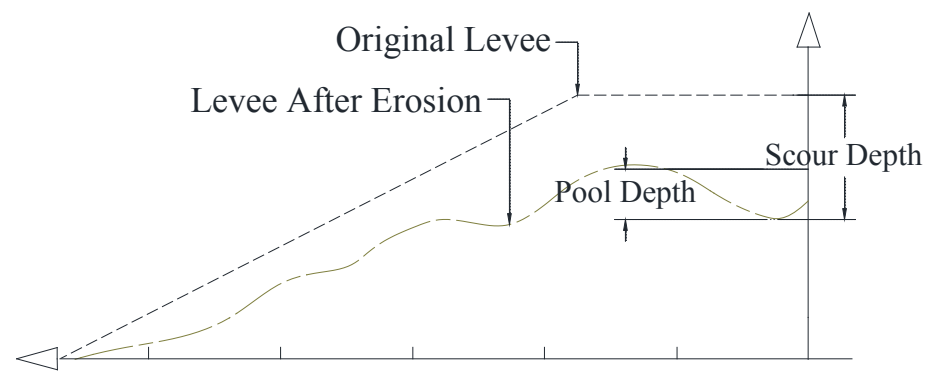

Figure 3. Sketch of a certain scour and pool depth for a leveefloodwall system

A drainage was cut in the container so that different pool depths can be created by draining water out of the container to a certain depth. Then, the elevation of the arm was lowered at intervals of $0.0127 \mathrm{~m}$ to imitate various scour depths. Then, the container was filled with water to a certain depth to represent various pool depths. Then, the induced shear stress was measured for different pool depths. This procedure was followed for 10 different elevations (i.e. scour depths) which had intervals of $0.0127 \mathrm{~m}$. Using the aforementioned procedure, a plot of induced shear stress for various pool depths and scour depths was developed for 1:20 scale and is shown in Figure 4. Different symbols in Figure 4 represent various scour depths for which the induced shear stress is measured at various pool depths. It was shown that the induced shear stress decreases by as the pool depth increases regardless of the scour depth.

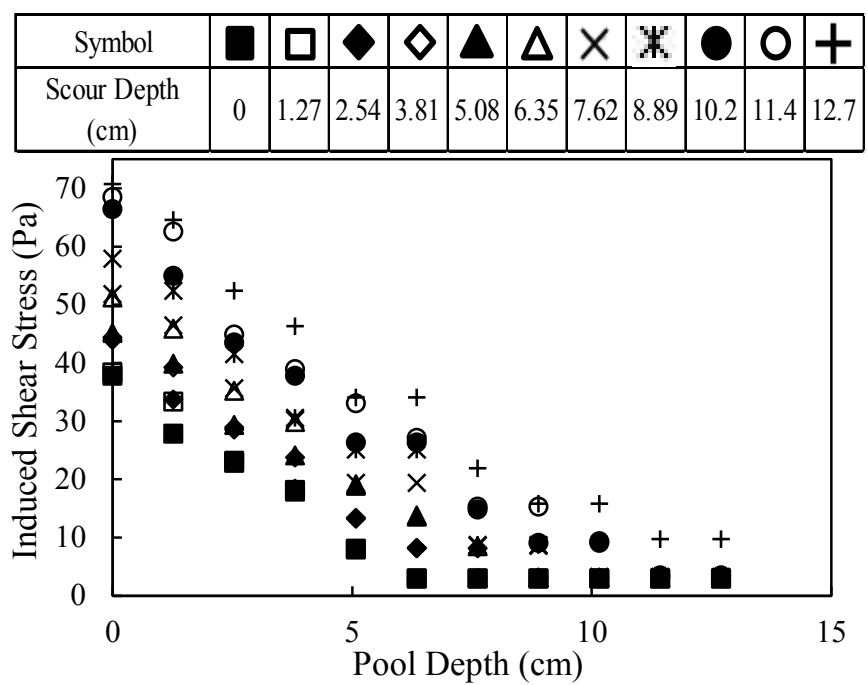

Figure 4. Induced shear stress measurements for 1:20 scaled levee-floodwall

\section{RESULTS AND DISCUSSION}

\subsection{Erosion Characteristics}

Induced shear stress, as the prominent eroding factor, is reduced by gradual generation of the pool at the crest of the levee resulting in decrease of erosion rate of every levee-floodwall test that was run in this study. In the beginning of the overtopping, the levee shows resistance for a short period; however, high erosion rate was observed after the scouring started and maintained until the pool generation initiated. As the pool depth increased as a result of increase of scour depth, a diminution in erosion rate was observed until it gradually became constant. The erosion would continue with a constant rate until the levee was washed away. Figure 5 shows the results of erosion rate throughout the test period for the 1:20 scaled model tests. Figure 6 shows the results of erosion rate throughout the test period for the 1:2 scaled model tests. 


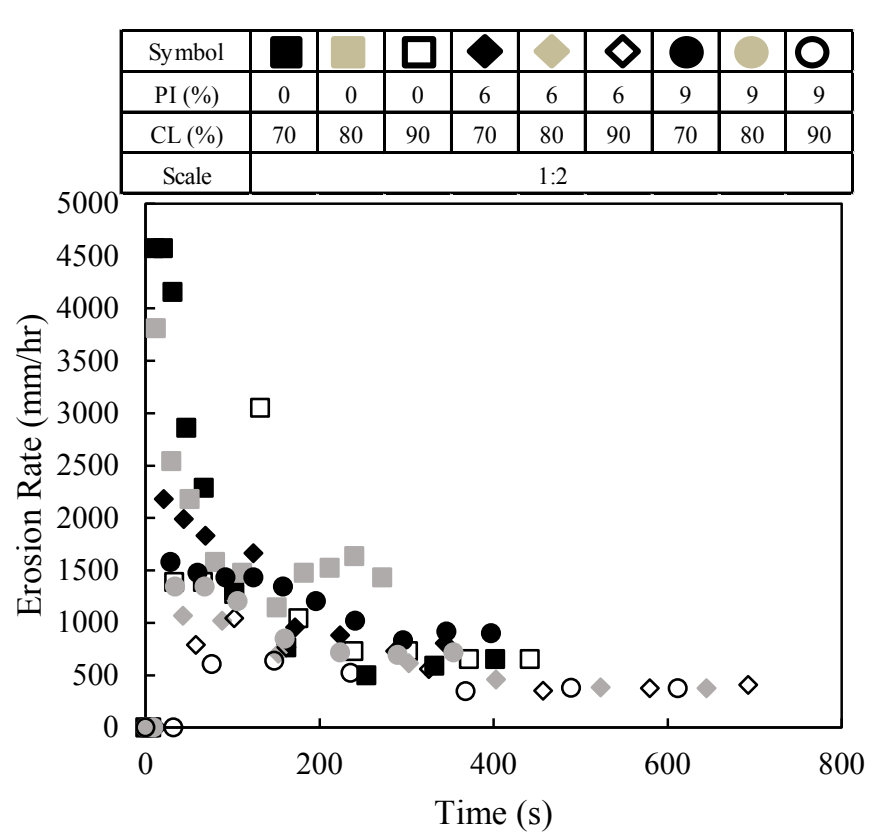

Figure 5. 1:20 scaled levee-floodwall results as a function of time

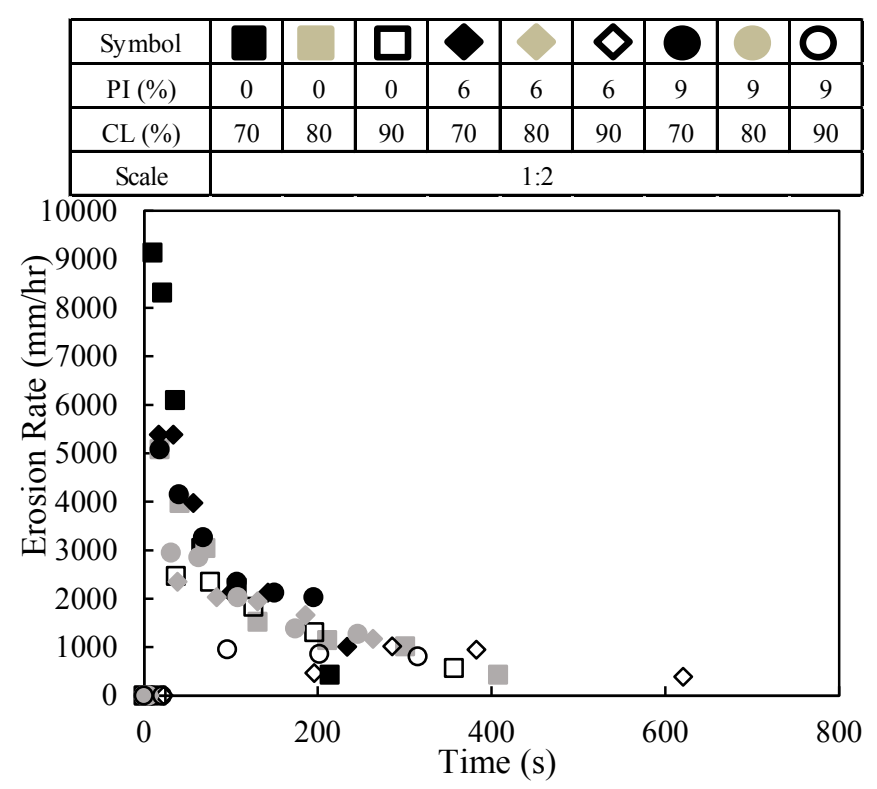

Figure 6. 1:2 scaled levee-floodwall results as a function of time

\subsection{Equilibrium Shear Stress Correlation}

As shown in Figure 5 and 6 the erosion rate becomes constant after a certain pool depth is generated. In that condition which is defined as equilibrium condition herein, the pool depth and scour depth reach to a balance where the induced shear stress remains constant. Consequently, the erosion rate stops reducing and continues eroding the levee with a constant rate. The shear stress that is being applied to the levee remains constant; nevertheless, this shear stress is not the critical shear stress and it is defined as equilibrium shear stress in this article. Equilibrium shear stress was achieved at approximately 300 and 200 seconds at scour depths of about
12 and $20 \mathrm{~cm}$ for $1: 20$ and $1: 2$ scales, respectively. For the 1:2 scaled model, the equilibrium was reached earlier than 1:20 because of higher erosion rate and faster pool generation. After that, the crest would continue eroding at a constant rate. During the storm events, if the floodwall overflows, due to the height of the floodwall, water freefall will apply a higher shear stress to the soil than critical shear stress. By back calculation from the equations derived from Figure 4, it was found that with scour depth of $50 \mathrm{~cm}$ and pool depth of $35.5 \mathrm{~cm}$ the induced shear stress will be equal to critical shear stress. For a full-sized levee with water impingement with high velocities these depths are going to be drastically higher and less likely to occur before failure; therefore, critical shear stress is less likely to be achieved in a full scale levee-floodwall systems. However, equilibrium shear stress is more likely to happen after pool is generated. Hence, knowing the equilibrium shear stress is critical in an overtopping event.

In section 4, the method proposed by this study to measure induced shear stress at different scour depths with various pool depths for a leveefloodwall system was explained. For each test, the pool and scour depth in which the erosion rate became constant was documented. Then, with use of Figure 4, the induced shear stresses were interpolated for certain pool and scour depths. Also, the equilibrium shear stress was calculated for the depths corresponding to constant erosion rate. The equilibrium shear stress was calculated for each test conducted in this article and the following correlation was proposed for materials considering correction coefficients for various compaction levels and plasticity indices:

$$
\tau_{e q}(P a)=9.065 \times \delta_{P I} \times \delta_{C L}
$$

where $\delta_{P I}=$ plasticity coefficient; and $\delta_{C L}=$ compaction level coefficient. The coefficients can be found in Table 2.

Table 2. Coefficients of equilibrium shear stress equation

\begin{tabular}{rlll}
\hline $\begin{array}{c}\text { PI } \\
(\%)\end{array}$ & $\boldsymbol{\delta}_{\boldsymbol{P I}}$ & $\mathbf{C . L}(\%)$ & $\boldsymbol{\delta}_{\boldsymbol{C L}}$ \\
\hline 0 & 1 & 70 & 1 \\
\hline 6 & 1.153 & 80 & 1.198 \\
\hline 9 & 1.252 & 90 & 1.466 \\
\hline
\end{tabular}

To verify Equation 1, the equilibrium shear stress was measured for 9 levee-floodwall 1:2 scaled model tests. These shear stresses were not used in creation of Equation 1. As shown in Figure 7, Equation 1 provides a reasonable agreement between measured and predicted equilibrium shear stresses. 


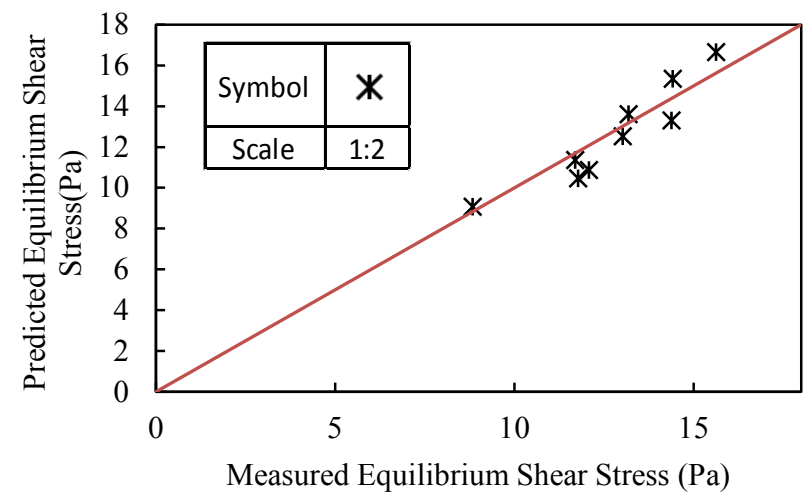

Figure 7. 1:2 scaled model measured equilibrium shear stress compared to the predicted values from Equation 1.

\subsection{Equilibrium Shear Stress vs. PI and CL}

In this section, induced shear stress at equilibrium condition is discussed with respect to compaction level and plasticity index. Figure $8 \& 9$ show the measured equilibrium shear stress for the conducted levee tests in scales of 1:20 and 1:2, respectively. It can be observed that the equilibrium shear stress increases when PI and CL increase. For example, for PI of 0 , the equilibrium shear stress increases $18 \%$ as the CL increases from $70 \%$ to $80 \%$. For CL of $70 \%$, it can also be observed that the equilibrium shear stress increases $22 \%$ as the PI increases from 0 to $6 \%$.

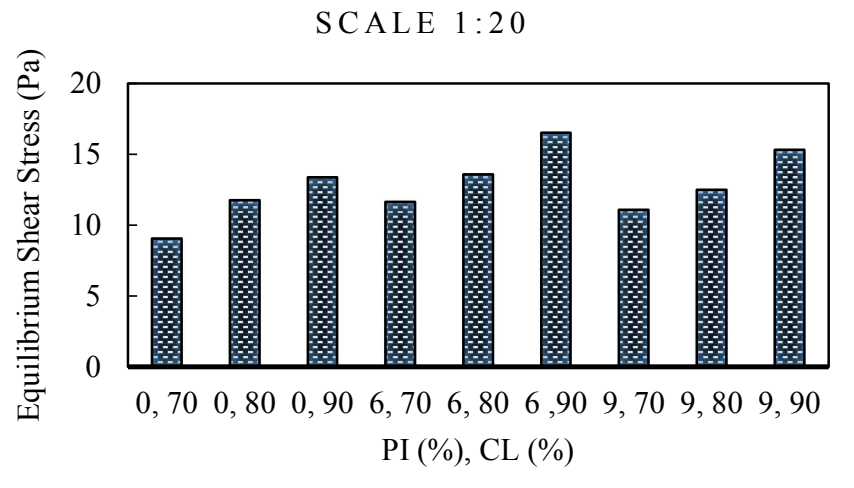

Figure 8. Equilibrium shear stress vs. PI and CL for 1:20 scale

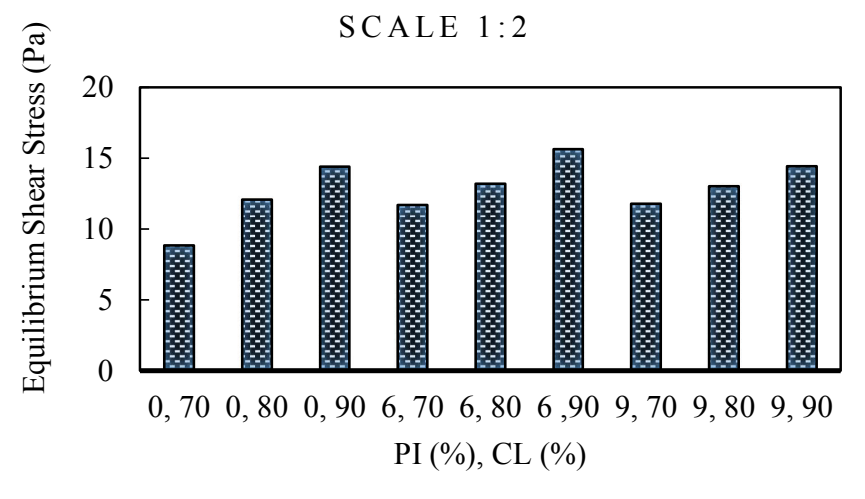

Figure 9. Equilibrium shear stress vs. PI and CL for 1:2 scale

\section{CONCLUSION}

Overtopping floodwall in levees is one of the main causes of levee failure. In storm events, as the water impinges the levee crest, it erodes the levee until the floodwall fails. Levee failure can have catastrophic consequences in urban areas and roads. Induced shear stress as the main cause of erosion is a vital subject to study. As scouring continues, a pool of water will generate at the levee crest. The results of this study conducted on eighteen simulated leveefloodwall tests showed that the pool can have mitigation effects on the induced shear stress and will decrease the erosion rate to a point where it becomes constant. In this article, equilibrium shear stress was introduced as the induced shear stress on the levee crest when constant erosion rate is observed during overtopping achieved. Two sets of 1:20 and 1:2 scaled levee-floodwall systems were utilized, and equilibrium shear stress was measured for each one of them. A prediction model was proposed to predict equilibrium shear stress based on soil characteristics using 1:20 scale test results. The equation was then verified using 1:2 scale test results. For future studies, equilibrium shear stress can be measured for more variety of plasticity indices and compaction levels. Saturation ratio is also a soil property that is likely to impact the values of equilibrium shear stresses.

\section{REFERENCES}

Briaud, J., Ting, F., Chen, H., Cao, Y., Han, W., \& Kwak, K. (2001). Erosion function apparatus for scour rate predictions. Journal of geotechnical and geoenvironmental engineering, 105-113.

Clark, L. A., \& Wynn, T. M. (2007). Methods for determining streambank critical shear stress and soil erodibility: Implications for erosion rate predictions. Transactions of the ASABE, 50(1), 95-106.

Dunn, I. S. (1959). Tractive resistance of cohesive channels. $J$. Soil Mech and Foundations Div., 85(SM3), 1-24.

Foley, M. G., \& Vanoni, V. A. (1977). Pulsing flow in steep alluvial streams. ASCE Journal of Hydraulic Div., 843-850. 
Hanson, G. J., \& Cook, K. R. (2004). Apparatus, test procedures, and analytical methods to measure soil erodibility in situ. Applied engineering in agriculture, 455462.

Hanson, G., Robinson, K., \& Cook, K. (2002). Scour bellow an everfall: Part II. Prediction. Transactions of the ASAE, 957964.

Hollick, M. (1976, November). Towards a routine test for the assessment of the critical tractive forces of cohesive soils. Transactions of the American Society of Agricultural Engineers, pp. 1076-1081.

Julian, J. P., \& Torres, R. (2006). Hydraulic erosion of cohesive riverbanks. Geomorphalogy, 76(1-2), 193-206.

Neill, C. (1967). Mean-velocity criterion for scour of coarse uniform bed material. Proc. Int. Assoc. Hydaul. Res., pp. 46-54.

Smerdon, E. T., \& Beasley, R. P. (1961). Critical tractive forces in cohesive soils. Agric. Eng., 42(1), 26-29.

Vanoni, V. A. (n.d.). New York, N.Y. : ASCE.

Villarini, G., Smith, J., Baeck, M., \& Krajewski, W. (2011). Examining flood frequency distributions in the Midwest U.S. American water resources association, (p. 447). 